RESENHAS 


\section{O BRASIL DE LULA}

O Brasil de Lula: A Gestão da Esperança. Direção de Gonzalo Aríjon. Paris: Dissidentes \& Arte France, 2005. Distribuição de First Run/Icarus Films, Nova York. 1 vídeo-disco (62 minutos), son., color.*

John D. French**

Palavras-chave: documentário, governo Lula, re-eleição.

Keywords: documentary, Lula's administration, re-election.

Este excelente documentário do diretor uruguaio Gonzalo Arijon foi rodado após os dois primeiros anos do mandato presidencial de Luiz Inácio Lula da Silva, do Partido dos Trabalhadores (PT) brasileiro. Eleito em 2002, o antigo sindicalista abraçou as políticas neoliberais as quais se opôs por muito tempo, nisso inclusa a austeridade fiscal que impedia um aumento imediato nos investimentos sociais. Quando este filme colorido de sessenta e dois minutos foi lançado, a administração de Lula havia sido devastada pelo funesto escândalo de corrupção de 2005, que levou a uma avalanche de demissões, a rumores de impeachment do presidente e a uma grande queda na popularidade de Lula. Ao invés de tornar o filme irrelevante, os acontecimentos subseqüentes ressaltaram sua presciência por ter captado a dinâmica que levou à impressionante reeleição de Lula em 2006, com 61\% dos votos válidos.

Então onde é possível encontrar a esperança a que o título do filme se refere? A resposta começa a aparecer quando Chico Whitaker, um dos idealizadores brasileiros do Fórum Social Mundial (FSM), fundado em 2001 em Porto Alegre, descreve a esperança extraordinária na posse de Lula, em 2003, como uma emoção tão poderosa que chegava a doer. Afinado com a retórica de Lula, Whitaker descreve o Brasil como uma nação dividida por violentas desigualdades, com 50 milhões no topo, completamente integrados ao sistema capitalista moderno, e 140 milhões de pobres na base. Fazendo uso dos slogans da campanha eleitoral de Lula, ele descreve o Brasil não como um país pobre, mas como um

\footnotetext{
* Tradução de Juliana Ferrari Guide

** Professor associado da Duke University e autor de $O A B C$ dos Operários: conflitos e alianças de classe em São Paulo, 1900-1950 (HUCITEC, 1995).
} 
país com muitas pessoas pobres, enquanto Lula declara que a fome é resultado não da falta de comida, mas da falta de vergonha daqueles que governam o país.

A partir deste início, o filme retraça a trajetória pessoal de Lula, tendo como protagonistas uma série de vozes eloqüentes de pobres vindas do "outro Brasil, o Brasil de Lula". Ouvimos o lendário cozinheiro do Sindicato dos Metalúrgicos de São Bernardo, onde Lula liderou as famosas greves de 1979 e 1980, bem como Gilberto dos Santos Souza, trabalhador da indústria automobilística, afro-descendente, e membro do PT. As palavras deles fornecem evidências claras da poderosa identificação que é tecida a partir da origem de Lula na miséria do Pernambuco rural, onde o filme começa, e ao longo de sua migração para a grande cidade industrial de São Paulo, e a eleição como primeiro presidente operário do país. Na cidade natal de Lula, encontramos seu primo Antonio de Mello Ferreira (que diz que o Fome Zero de Lula "é pouco, mas ajuda") e acompanhamos profissionais da saúde que visitam domicílios rurais pobres para pesar as crianças desnutridas, como parte da campanha Fome Zero do governo.

O filme então se desloca para São Paulo, onde visitamos sem-tetos que ocupam um prédio de apartamentos abandonados: famílias que combinam luta, resignação e esperança por suas crianças enquanto forem ajudadas pelas doações contra a fome do governo. Foi em São Paulo, onde tantos milhões migraram em meados do século, que Lula entrou na parte mais baixa dos 50 milhões do topo, como trabalhador da indústria moderna. Após visitar a fábrica Daimler-Chrysler, testemunhamos uma longa discussão de boteco entre metalúrgicos, orgulhosos de "um deles" dirigir o país e estar conseguindo fazê-lo com tanta competência, apesar das profecias de desastre econômico feitas antes de sua eleição. Enquanto equilibram a decepção política e a fragilidade da esperança, mostram uma aguda consciência dos obstáculos para a ação governamental ("ele gostaria de ir mais rápido, mas os eleitores brasileiros não deram a ele maioria no Congresso"). Na seqüência, os seguimos numa marcha para Brasília para reivindicar um aumento do salário mínimo, demanda apenas em parte atendida; ao menos desta vez, Gilson diz, a polícia não nos bateu e nós marchamos diretamente para um encontro com o presidente (e então vemos a afetuosa troca de abraços e saudações entre eles); além disso, Lula prometeu o restante do aumento para antes do fim de seu mandato.

O filme então se volta para a dimensão rural do equilíbrio que a administração de um país envolve. Ele justapõe a visão crítica de membros do Movimento dos Trabalhadores 
Sem-Terra (MST) àquela dos grandes proprietários que, como Whitaker observa, podem não ser parte da base de apoio à Lula, mas tem um poder de fogo que o presidente certamente não pode ignorar. Um proprietário aponta que Lula tem sido razoável, acendendo uma vela para o capitalismo e outra para o socialismo, mas o governo deveria parar de importunar, uma vez que a economia do Brasil é sustentada pelos excedentes comerciais gerados pelo agronegócio brasileiro; a agricultura familiar pode ser uma prioridade social, mas certamente não é uma prioridade econômica.

Desta forma, o filme constrói seu objetivo geral: "avaliar o longo e turbulento caminho adiante, uma trilha estreita onde esperança e interesses econômicos colidem com freqüência". Mas é realmente possível "administrar" a esperança sob limites tão estreitos? Aqui o filme coloca o posicionamento maduro, crítico e equilibrado que caracterizou a esquerda brasileira no meio do primeiro mandato de Lula. Fala Frei Betto, um famoso teólogo da libertação, explicando que não se pode exigir de Lula resultados de uma Revolução quando tudo que ele fez foi ganhar uma eleição, o que permite, na melhor das hipóteses, a conquista de pequenas parcelas de poder. Ao reconhecer o limitado espaço de manobra de Lula, Frei Betto expressa a esperança de que Lula saberá como conduzir o processo de mudança através de caminhos não familiares para a esquerda. Aqui, o filme nos apresenta à esperança, vista como a confiança num político a quem se está ligado de maneira profunda, poderosa e pessoal. Ao mesmo tempo em que não abandona a aspiração radical, a maioria da esquerda no Brasil entendeu que a esperança é algo que não se pode perder numa guerra de manobras políticas. Nas palavras do líder do FSM, Candido Grzyowski, o governo de Lula seria melhor se estivesse sujeito às pressões dos movimentos sociais, paralisados em face de um governo protegido pela sua imagem. Ou, como Whitaker explica, "uma vitória política ajuda. É necessária, mas não é a resposta para os nossos problemas. Nós somos todos co-responsáveis por este governo" e "nossa sociedade civil tem de se mobilizar para enfrentar o monstro da desigualdade, e esse desenvolvimento seria muito bem visto por Lula".

O filme também nos mostra a coléra da esperança decepcionada quando Lula discursou no FSM de Janeiro de 2005, em Porto Alegre. Aclamado em 2003, em seu retorno Lula encontra uma vaia contínua de uma parcela significativa da platéia do estádio, que o chamava de traidor enquanto cantava "lula, que triste, operário governando pra elite". A esperança frustrada da esquerda viraria fúria num momento posterior ao registrado pelo 
filme, em meados de 2005, quando ficou claro que o PT era "um partido como os outros" no sistema político notoriamente corrupto do Brasil. De fato, a deserção do eleitorado mais à esquerda frustrou os esforços de Lula para agarrar seu segundo mandato já no primeiro turno da eleição de 1 o de outubro de 2006. Ele não conseguiu chegar aos 50\% necessários porque nove milhões de brasileiros, ou seja, 9,5\% dos votos válidos, deram seu apoio a dois políticos que haviam saído do PT num protesto duro contra as inadequações do governo.

Ainda assim, a cena do FSM ilustra a dinâmica complicada da esperança, porque as críticas estão exigindo o fim da traição da esperança, e nem todos no estádio vaiam. Uma vez que Lula se levanta para falar, podemos ver a eficácia da sua política, analisado como um trabalho corporificado feito com palavras. Diante do coro hostil, Lula declara que a fome é um problema político e não social e critica os brasileiros por olharem ao Norte, para a Europa e os Estados Unidos, e virar as costas não só para a América do Sul, mas também para a África. "Nós somos o segundo maior país negro depois da Nigéria", declara o presidente brasileiro, pegando até seus opositores de surpresa. Enquanto examina a liderança brasileira na luta contra a Organização Mundial do Comércio, os aplausos crescem conforme Lula termina, com sua marca registrada: "Eu sou de um estado pobre, Pernambuco, e lá quem não morre até os cinco anos é um lutador incansável". Em sua próxima aparição, Lula está num painel no Fórum Econômico Mundial de Davos com Bill Gates, onde é cortado sem cerimônia após pedir a eliminação da fome através de uma campanha internacional a ser financiada pela taxa Tobin sobre transações financeiras, ou por um imposto sobre a venda de armas.

Tendo observado os tropeços de seu programa Fome Zero, Lula o substituiu pelo programa Bolsa Família, que foi implantado a fundo e de maneira efetiva em 2006, com 11,1 milhão de famílias recebendo seus benefícios (ele varreu as regiões mais pobres com $60-85 \%$ dos votos). Mesmo o valor real do salário mínimo aumentou em um quarto em 2006 em comparação a 2002, como prometido. E quando a raiva da esquerda frustrou sua vitória no primeiro turno, Lula não somente ganhou de volta aqueles 9 milhões de votos, mas conquistou 2,5 milhões de votos do seu oponente (Wendy Hunter and Timothy J. Power, "Rewarding Lula," Latin American Politics and Society [2007]). Lula, o lutador incansável, venceu novamente, e agora, em seu segundo mandato, enfrenta o ainda mais árduo desafio de cultivar esperança, além de administrá-la. 